\title{
Evaluation of Factors Affecting Metastasis for Renal Cell Carcinoma Based on Current Guidelines in Japan
}

\author{
YOSHIFUI KADONO ${ }^{1}$, SHOHEI KAWAGUCHI ${ }^{1}$, TAKAHIRO NOHARA ${ }^{1}$, KAZUYOSHI SHIGEHARA $^{1}$, \\ KAZUTAKA NARIMOTO ${ }^{1}$, KOUJI IZUMI $^{1}$, HIROKO IKEDA $^{2}$, HIROSHI YAEGASHI $^{3}$, \\ TOHRU MIYAGI ${ }^{3}$, TAKAO NAKASHIMA ${ }^{3}$, CHIKASHI SETO ${ }^{4}$ and ATSUSHI MIZOKAMI ${ }^{1}$ \\ ${ }^{1}$ Department of Integrative Cancer Therapy and Urology, \\ Kanazawa University Graduate School of Medical Science, Kanazawa, Japan; \\ ${ }^{2}$ Department of Diagnostic Pathology, Kanazawa University Hospital, Kanazawa, Japan; \\ ${ }^{3}$ Department of Urology, Ishikawa Prefectural Central Hospital, Kanazawa, Japan; \\ ${ }^{4}$ Department of Urology, Toyama Prefectural Central Hospital, Toyama, Japan
}

\begin{abstract}
Background/Aim: To analyze the suitability for metastasis evaluation of each pathologic item on the Fourth Edition of the General Rule for Clinical and Pathologic Studies on Renal Cell Carcinoma in Japan. Patients and Methods: We retrospectively examined 457 cases of renal operation after 2011 using the current edition of the guidelines. Results: The mean postoperative follow-up period was 25.3 months. Radical nephrectomy was performed in 264 cases, whereas partial nephrectomy was performed in 193 cases. Including the 33 cases discovered after operation, the overall number of metastatic cases was 68 (14.9\%). Using the current edition of the guidelines, the items of histologic grade, morphology of tumor invasion, tumor pseudocapsule, and intrarenal metastasis were all correlated with distant metastasis. Conclusion: This is the first report showing that each item on the current Japanese guidelines for renal cell cancer was useful for predicting metastasis.
\end{abstract}

Chronic kidney disease (CKD) is a concept that has been widely recognized and has a vital prognosis that gets worse with decreasing renal function because of the relatively high probability of cardiovascular events (1). Recently, nephronsparing surgery (NSS) for small renal cell carcinoma (RCC)

Correspondence to: Dr. Yoshifumi Kadono, Department of Integrative Cancer Therapy and Urology, Kanazawa University Graduate School of Medical Science, 13-1 Takara-machi, Kanazawa, Ishikawa 920-8640, Japan. Tel: +81 762652393, Fax: +81762344263, e-mail: yskadono@yahoo.co.jp

Key Words: General rule for clinical and pathological studies, partial nephrectomy, metastasis, radical nephrectomy, renal cell carcinoma. has been reported to prevent renal function decline (2) and to be beneficial in improving overall survival $(3,4)$; therefore, NSS is recommended as often as possible (5).

NSS for RCC is supposed to provide the same cancerspecific survival (CSS) and progression-free survival (PFS) as radical nephrectomy does (6-9). One of the problems concerning NSS for RCC is avoidance of postoperative residual cancer, particularly in occult multifocal RCC, which is not detected by preoperative imaging (10). From the viewpoint of preserving renal function, tumor enucleation (TE) is a procedure that can be beneficial in preserving more renal parenchyma compared to partial nephrectomy (PN). In addition, the TE has been lately reported to have good outcomes in terms of cancer control $(11,12)$.

The presence of clear borders between the tumor and normal tissues is important to achieve complete resection of the tumor. Most RCCs have a pseudocapsule; for TE to achieve complete cancer resection there should be no cancer invasion outside the tumor capsule.

The General Rule for Clinical and Pathological Studies on RCC, Fourth Edition was published on April 2011 in Japan. In this guideline, items on the morphologies of tumor invasion and the tumor capsule were added to allow more detailed description of the local cancer conditions (13). In this present study, RCC tumors that were resected by radical nephrectomy ( $\mathrm{RN}$ ) or PN were pathologically evaluated using the current guidelines and were retrospectively analyzed, along with the suitability of each pathologic item for evaluation of metastasis. In addition, the indications of PN and RN for RCC were evaluated based on each pathological item. The relationship between tumor capsular formation and the pathological items were also evaluated. 


\section{Patients and Methods}

This study was conducted using the databases of Kanazawa University Hospital, Ishikawa Prefectural Central Hospital, and Toyama Prefectural Central Hospital, with the approval of the institutional review boards of all three hospitals. We retrospectively examined 457 cases of RCC that were treated by RN or PN between May 2011 and November 2016.

Preoperative CT, MRI, and bone scintigraphy were performed to assess the cancer stage in accordance with the classification of the Union for International Cancer Control Seventh Edition. The doctors in charge based their choice between PN and RN depending on the cancer stage, and PN was performed mostly in clinical T1a cases.

The resected specimens were fixed in $10 \%$ formalin solution, and cut at 4-5-mm slices for pathologic evaluation and diagnoses, in accordance with General Rule for Clinical and Pathological Studies on RCC, Fourth Edition. The histologic diagnoses were based on the 2004 WHO classification; whereas pathologic local progression was evaluated using Seventh Edition of the TNM classification that was published in 2009. Histologic grade was classified into three groups, according to the Japanese guidelines. Grade I (G1) was defined as a tumor with a nucleus that was smaller than that of a normal tubular cell; grade II (G2) was defined as a tumor with the same nuclear size as the normal; and grade III (G3) was defined as a tumor with a nucleus that was bigger than that of normal tissues, with or without pleomorphism or unusual pattern. GX was defined as the presence of a non-evaluable nucleus. For tumors that had several mixed nuclear patterns, the highest grade was designated as the grade of the cancer.

The pattern of the cancer invasion was described according to the infiltration (INF) to the surrounding tissue; INFa represented expansive proliferation, INFc represented invasive proliferation, and $\mathrm{INFb}$ was intermediate between INFa and INFc. Venous invasion and lymphatic invasion were designated as $\mathrm{v} 1$ and ly 1 , and no venous and lymphatic invasions were designated as v0 and ly0, respectively. The other pathological evaluations included expansive tumor growth and the presence of a clear border between cancer and normal tissues (eg) or invasive tumor growth towards the normal tissues without a pseudocapsule (ig); the presence of a clear pseudocapsule ( $\mathrm{fc} 1$ ) or the absence of a pseudocapsule ( $\mathrm{fc} 0$ ); the presence of ipsilateral intrarenal metastasis (im1) or the absence of intrarenal metastasis (im0); cancer infiltration into the renal fibrous capsule (rc-inf 1 ) or the absence of cancer infiltration into the renal fibrous capsule (rc-inf0); cancer infiltration to the renal pelvis (rp-inf1) or no cancer infiltration to the renal pelvis (rpinf0); cancer infiltration to the renal sinus fat (s-inf1) or no cancer infiltration to the renal sinus fat (s-inf0); and the resected surgical margin (SM), according to the presence (SM1) or the absence (SM0) of cancer cells.

Categorical variables were used to calculate the incidence and percentage of each factor. Continuous variables were presented as mean \pm standard deviation (SD). The unpaired Student's $t$-test and the chi-square test were used to evaluate for a possible statistical correlation. Metastasis-free survival was estimated using the Kaplan-Meier method, and the statistical significance of differences between groups was calculated using the log-rank test. All data analyses were performed using SPSS for Windows (SPSS Inc., Chicago, IL, USA). In all analyses, a $p$-value $<0.05$ was considered to be statistically significant.
Table I. Clinical feature of 457 analyzed kidneys of 453 patients.

\begin{tabular}{lc}
\hline Variable & Value \\
\hline Age, years $( \pm$ SD) & $63.1( \pm 12.0)$ \\
Gender & $333(72.9 \%)$ \\
Male & $120(27.1 \%)$ \\
Female & \\
Clinical metastasis* & $418(92.3 \%)$ \\
N0M0 & $4(0.9 \%)$ \\
N1-2M0 & $24(5.3 \%)$ \\
N0M1 & $7(1.5 \%)$ \\
N1-2M1 & \\
Multiple tumor* & $8(1.8 \%)$ \\
Unilteral & $5(1.1 \%)$ \\
Bilateral & \\
Tumor side & $219(48.9 \%)$ \\
Right & $230(50.0 \%)$ \\
Left & $5(1.1 \%)$ \\
Both & \\
Surgery & $264(57.8 \%)$ \\
Radical nephrectomy & $193(42.2 \%)$ \\
Partial nephrectomy & $25.3(1-64)$ \\
Mean follow-up, months (range) &
\end{tabular}

*diagnosed by imaging analysis preoperatively. SD: Standard deviation.

\section{Results}

In total, there were 453 patients recruited and evaluated in this study; the demographics of the patients are shown in Table I. Preoperative evaluation detected bilateral renal tumors in five cases; four cases underwent successive nephrectomies of both sides, whereas one case underwent unilateral nephrectomy. Therefore, because each case was evaluated independently, the total number of kidneys evaluated in this study was 457 .

RN was performed on 264 cases, whereas PN was performed on 193 cases. Preoperative evaluation detected metastasis in 35 cases $(7.7 \%)$, all of which underwent RN. The mean follow-up period after operation was 25.3 months. Table II shows a comparison of the pathological features between PN and RN. The pathologic findings showed higher grade of malignancy and more locally invasive tumors in the RN group than in the PN group. The SM status in all patients in the PN group was negative; the cases with SM1 status in the RN group were pT3-4 due to local invasion and adhesion.

Each item was evaluated pathologically for its association with metastasis. If the 33 cases of metastasis detected after operation are included, the total number of metastatic cases was 68 cases $(14.9 \%)$. The metastatic sites were the lungs alone in 34 cases, the lymph node alone in 3 cases, and the bone alone in 4 cases. Pulmonary metastasis with multiple metastases to the organs was seen in 53 cases, accounting for 
Table II. Clinical and pathological features of 457 analyzed kidneys.

\begin{tabular}{|c|c|c|c|c|}
\hline Variable & All & Partial Nx & Radical Nx & $p$-Value \\
\hline Number of cases & 457 & 193 & 264 & \\
\hline Pathologic tumor size, $\mathrm{cm}( \pm \mathrm{SD})$ & $3.9( \pm 2.6)$ & $3.2( \pm 0.9)$ & $5.2( \pm 2.7)$ & $<0.001$ \\
\hline Pathologic tumor stage & & & & $<0.001$ \\
\hline pT1a & $277(60.6 \%)$ & $178(64.3 \%)$ & $99(37.5 \%)$ & \\
\hline pT1b & $58(12.7 \%)$ & $5(2.6 \%)$ & $53(20.1 \%)$ & \\
\hline pT2 & $16(3.5 \%)$ & $0(0 \%)$ & $16(6.1 \%)$ & \\
\hline pT3a & $96(21.0 \%)$ & $10(10.4 \%)$ & $86(32.6 \%)$ & \\
\hline pT3b & $5(1.1 \%)$ & $0(0.0 \%)$ & $5(1.9 \%)$ & \\
\hline pT3c & $1(0.2 \%)$ & $0(0.0 \%)$ & $1(0.4 \%)$ & \\
\hline pT4 & $4(0.9 \%)$ & $0(0.0 / \%)$ & $4(1.5 \%)$ & \\
\hline Nuclear grade & & & & $<0.001$ \\
\hline $\mathrm{G} 1$ & $37(8.1 \%)$ & $21(10.9 \%)$ & $16(6.1 \%)$ & \\
\hline $\mathrm{G} 2$ & $303(66.3 \%)$ & $147(76.2 \%)$ & $156(59.0 \%)$ & \\
\hline G3 & $110(24.1 \%)$ & $23(11.9 \%)$ & $87(33.0 \%)$ & \\
\hline Undeterminable & $7(1.5 \%)$ & $2(1.0 \%)$ & $5(1.9 \%)$ & \\
\hline Histologic subtype & & & & 0.177 \\
\hline Clear cell & $399(87.2 \%)$ & $176(91.2 \%)$ & $223(84.4 \%)$ & \\
\hline Papillary & $24(5.3 \%)$ & $8(4.1 \%)$ & $16(6.1 \%)$ & \\
\hline Chromophobe & $14(3.1 \%)$ & $4(2.1 \%)$ & $10(3.8 \%)$ & \\
\hline Others & $20(4.4 \%)$ & $5(2.6 \%)$ & $15(5.7 \%)$ & \\
\hline INF & & & & $<0.001$ \\
\hline $\mathrm{a}$ & $353(77.2 \%)$ & $170(88.1 \%)$ & $183(69.3 \%)$ & \\
\hline $\mathrm{b}$ & $102(22.3 \%)$ & $23(11.9 \%)$ & $79(29.9 \%)$ & \\
\hline c & $2(0.4 \%)$ & $0(0.0 \%)$ & $2(0.8 \%)$ & \\
\hline v1 & $236(51.6 \%)$ & $57(29.5 \%)$ & $179(67.8 \%)$ & $<0.001$ \\
\hline ly1 & $47(10.3 \%)$ & $6(3.1 \%)$ & $41(15.5 \%)$ & $<0.001$ \\
\hline ig (eg/ig) & $75(16.4 \%)$ & $19(9.8 \%)$ & $56(21.2 \%)$ & 0.001 \\
\hline $\mathrm{fc} 1$ & $344(75.3 \%)$ & $152(78.8 \%)$ & $192(72.7 \%)$ & 0.140 \\
\hline $\operatorname{im} 1(n=350)^{*}$ & $9(2.6 \%)$ & $1 / 97(1.0 \%)$ & $8 / 253(3.2 \%)$ & 0.260 \\
\hline rc-inf & $86(18.8 \%)$ & $19(9.8 \%)$ & $67(25.4 \%)$ & $<0.001$ \\
\hline $\mathrm{rp}$-inf $(\mathrm{n}=357)^{*}$ & $20(5.6 \%)$ & $1 / 96(1.0 \%)$ & $19 / 261(7.3 \%)$ & 0.023 \\
\hline s-inf $(n=364)^{*}$ & $53(14.6 \%)$ & $3 / 105(2.9 \%)$ & $53 / 259(19.3 \%)$ & $<0.001$ \\
\hline SM1 & $11(2.4 \%)$ & $0(0.0 \%)$ & $11(4.2 \%)$ & 0.016 \\
\hline Metastasis $(+)^{* * *}$ & $68(14.9 \%)$ & $3(1.6 \%)$ & $65(24.6 \%)$ & $<0.001$ \\
\hline
\end{tabular}

$*(\mathrm{n}=)$ Case number, $* *$ including post-operative metastasis. Nx: Nephrectomy; INF: Infiltration; v: venous infiltration; ly: lymphatic infiltration; eg: expansive growth; ig: invasive growth; fc: false capsule; im: intrarenal metastasis; rc-inf: renal capsule- infiltration; rp-inf: renal pelvis-infiltration; s-inf: sinus-infiltration; SM: surgical margin; SD: standard deviation.

$77.9 \%$ of all metastatic cases. As shown in Figure 1, each item in the General Rule for Clinical and Pathological Studies on RCC was associated with metastasis.

Multiple ipsilateral renal tumors were detected by preoperative evaluation in 8 cases $(1.8 \%$ ) (Table I); pathological evaluation of these cases suggested that 7 cases were concurrent tumors, whereas the remaining case, which had pulmonary metastasis, was designated as im1. Table II shows that nine cases were diagnosed as ipsilateral im1. For the nine cases, the average size of the main tumor was $6.0 \mathrm{~cm}$ (range $=4-10 \mathrm{~cm}$ ) and was larger than that of the concurrent renal tumor cases $(3.4 \mathrm{~cm})$ (Table III). The probability of distant metastasis was significantly higher in 5 of $9(55.6 \%)$ cases with ipsilateral im1 than in 1 of 14 cases $(7.1 \%)$ with ipsilateral synchronous multiple cancers
(Table III). Preoperative evaluation of the im1 RCC cases for distant metastases was positive in five cases and negative in the other four cases. Of the nine cases evaluated as im1 by pathological examination, eight cases that were diagnosed as at least clinical stage $\mathrm{T} 1 \mathrm{~b}$ (cT1b) by preoperative evaluation underwent $\mathrm{RN}$, whereas the remaining case, which had a 4cm-diameter tumor and was diagnosed as cT1 by preoperative evaluation, underwent PN (Table II). From the results of pathologic staging of the im1 cases, only the PN case was classified as pathologic T1a (pT1a); the other RN cases were at least pT3a (Table III). In the im1 case that underwent $\mathrm{PN}$, a satellite cancer with $0.6 \mathrm{~mm}$ diameter was noted near the main tumor, but no recurrence or metastasis was observed. All 193 PN cases did not develop any local recurrence during the follow-up period. 
(A) Nuclear grade

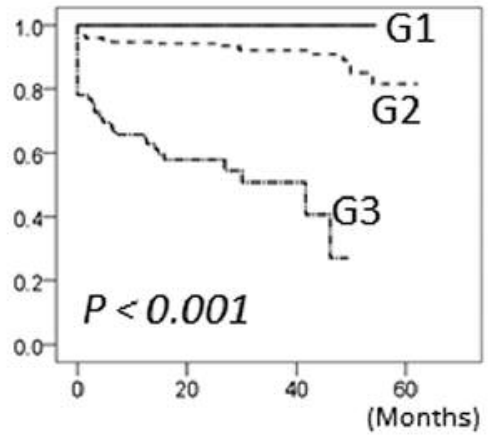

(D) eg/ig

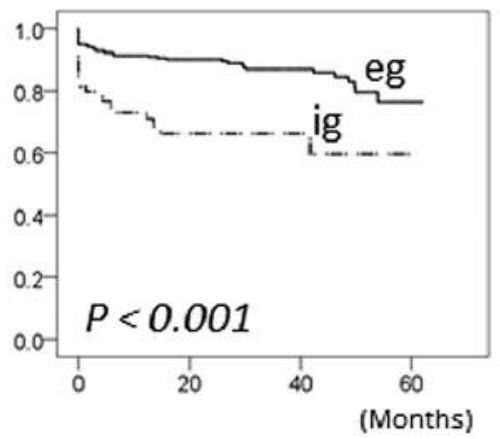

(G) fc0/1

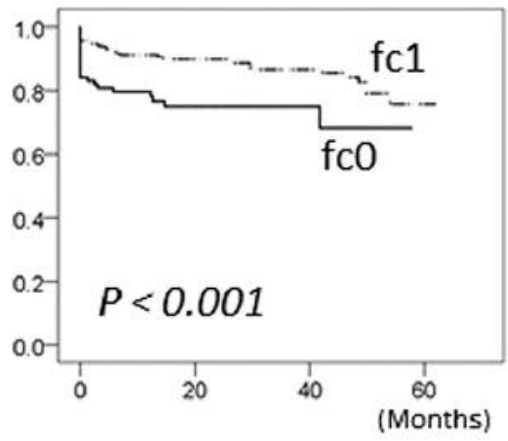

\section{(J) rp-info/1}

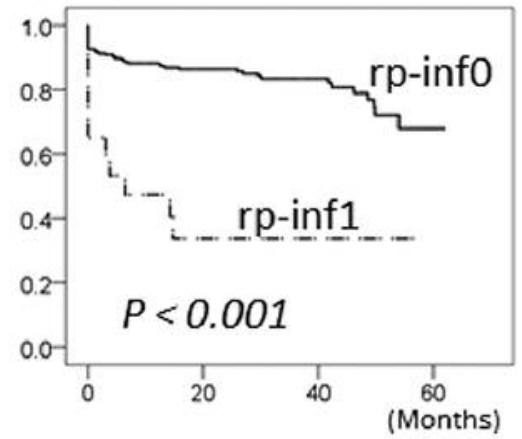

(B) $I N F a / b / c$

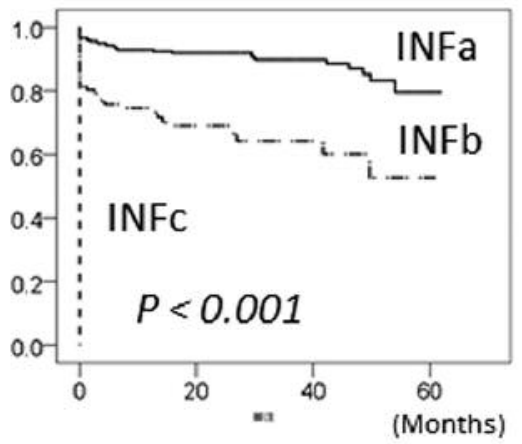

(E) vo/1

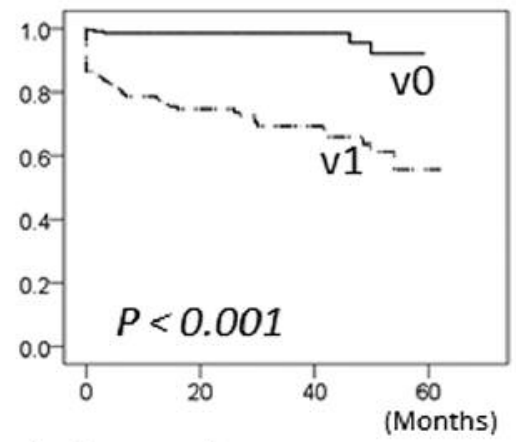

(H) imo/1

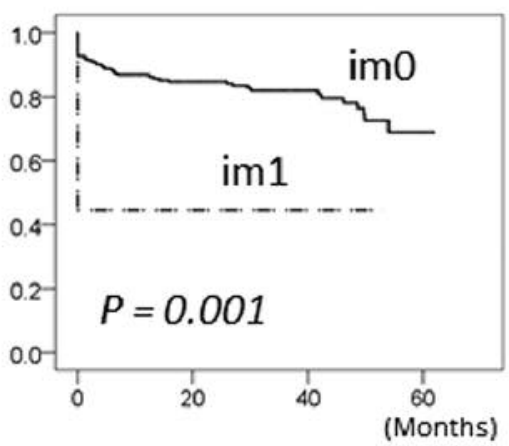

(K) s-info/1

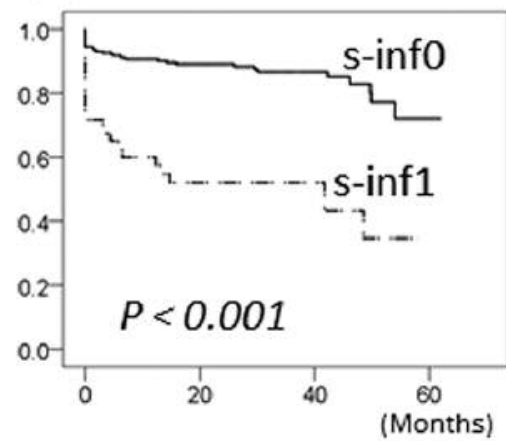

(C) Sarcomatous

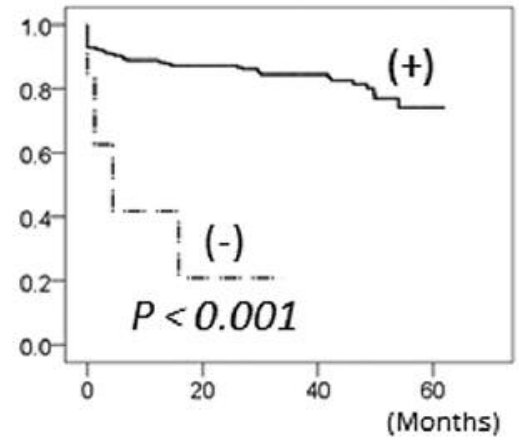

(F) ly0/1

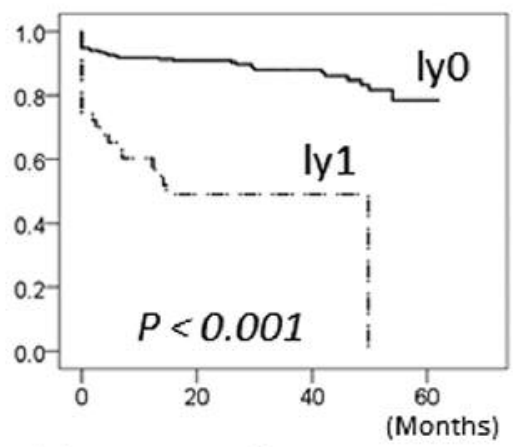

(I) rc-info/1

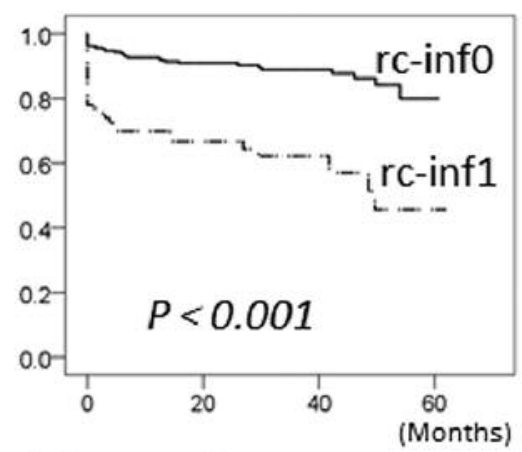

\section{(L) $\mathrm{SMO} / 1$}

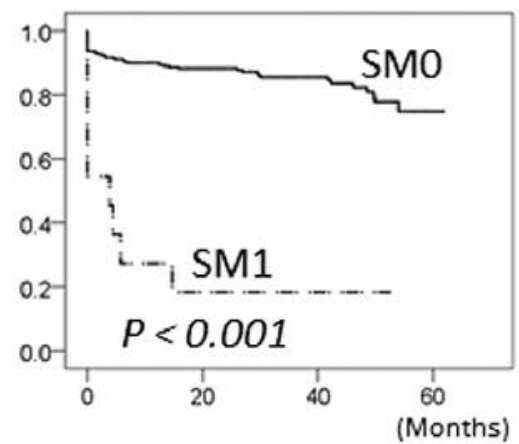

Figure 1. Metastasis-free survival analysis in each pathological item; (A) nuclear grade; (B) INF: infiltration; (C) with sarcomatous component; $(D)$ eg: expansive growth; ig: invasive growth; $(E)$ v: venous invasion; $(F)$ ly: lymphatic invasion; $(G)$ fc: false capsule; $(H)$ im: intrarenal metastasis; (I) rc-inf: renal capsule- infiltration; (J) rp-inf: renal pelvis-infiltration; (K) s-inf: sinus-infiltration; (L) SM: surgical margin. 
Table III. Clinical and pathological features of ipsilateral renal multiple cancers.

\begin{tabular}{|c|c|c|c|c|}
\hline Variable & All & $\operatorname{im} 0$ & im1 & $p$-Value \\
\hline number (bilateral case) & $23(5)$ & $14(5)$ & $9(0)$ & \\
\hline Clinical tumor stage & & & & 0.001 \\
\hline $\mathrm{cT} 1$ & $16(69.6 \%)$ & $14(100 \%)$ & $2(22.2 \%)$ & \\
\hline $\mathrm{cT} 2$ & $1(4.3 \%)$ & $0(0.0 \%)$ & $1(11.1 \%)$ & \\
\hline cT3 & $5(21.7 \%)$ & $0(0.0 \%)$ & $5(55.6 \%)$ & \\
\hline cT4 & $1(4.3 \%)$ & $0(0.0 \%)$ & $1(11.1 \%)$ & \\
\hline $\mathrm{cM} 1 *$ & $6(26.1 \%)$ & $1(7.1 \%)$ & $5(55.6 \%)$ & 0.010 \\
\hline Occult multifocal & $10(43.5 \%)$ & $2(14.3 \%)$ & $8(88.9 \%)$ & $<0.001$ \\
\hline main tumor size, $\mathrm{cm}( \pm \mathrm{SD})$ & $4.4( \pm 2.4)$ & $3.4( \pm 1.9)$ & $6.0( \pm 2.3)$ & 0.007 \\
\hline Pathologic tumor stage & & & & 0.004 \\
\hline pT1 & $14(61.0 \%)$ & $13(92.9 \%)$ & $1(11.1 \%)$ & \\
\hline pT2 & $0(0.0 \%)$ & $0(0.0 \%)$ & $0(0.0 \%)$ & \\
\hline pT3 & $8(34.7 \%)$ & $1(7.1 \%)$ & $7(77.8 \%)$ & \\
\hline pT4 & $1(4.3 \%)$ & $0(0.0 \%)$ & $1(11.1 \%)$ & \\
\hline Nuclear grade $* *$ & & & & 0.575 \\
\hline G1 & $1(4.3 \%)$ & $1(7.1 \%)$ & $0(0.0 \%)$ & \\
\hline $\mathrm{G} 2$ & $14(60.9 \%)$ & $9(64.3 \%)$ & $5(55.6 \%)$ & \\
\hline G3 & $8(34.8 \%)$ & $4(28.6 \%)$ & $4(44.4 \%)$ & \\
\hline Histologic subtype & & & & 0.486 \\
\hline Clear cell & $17(73.9 \%)$ & $10(71.5 \%)$ & $7(77.8 \%)$ & \\
\hline Papillary & $4(17.4 \%)$ & $3(21.4 \%)$ & $1(11.1 \%)$ & \\
\hline Chromophobe & $0(0.0 \%)$ & $0(0.0 \%)$ & $0(0.0 \%)$ & \\
\hline Others & $2(8.7 \%)$ & $1(7.1 \%)$ & $1(11.1 \%)$ & \\
\hline INF & & & & 0.196 \\
\hline $\mathrm{a}$ & $14(60.9 \%)$ & $10(71.4 \%)$ & $4(44.4 \%)$ & \\
\hline $\mathrm{b}$ & $9(39.1 \%)$ & $4(28.6 \%)$ & $5(55.6 \%)$ & \\
\hline $\mathrm{c}$ & $0(0.0 \%)$ & $0(0.0 \%)$ & $0(0.0 \%)$ & \\
\hline v1 & $14(60.9 \%)$ & $5(35.7 \%)$ & $9(100 \%)$ & 0.002 \\
\hline ly1 & $4(17.4 \%)$ & $1(7.1 \%)$ & $3(33.3 \%)$ & 0.106 \\
\hline ig (eg or ig) & $7(30.4 \%)$ & $5(35.7 \%)$ & $2(22.2 \%)$ & 0.493 \\
\hline $\mathrm{fc} 1$ & $13(56.5 \%)$ & $8(57.1 \%)$ & $5(55.6 \%)$ & 0.940 \\
\hline rc-inf & $6(26.1 \%)$ & $1(7.1 \%)$ & $5(55.6 \%)$ & 0.010 \\
\hline rp-inf $(\mathrm{n}=21)^{* * *}$ & $2(9.5 \%)$ & $1(8.3 \%)$ & $1(11.1 \%)$ & 0.830 \\
\hline $\operatorname{s-inf}(\mathrm{n}=21)^{* * *}$ & $8(38.1 \%)$ & $1(8.3 \%)$ & $7(77.8 \%)$ & 0.001 \\
\hline Metastasis $(+)^{* * * *}$ & $6(26.1 \%)$ & $1(7.1 \%)$ & $5(55.6 \%)$ & 0.010 \\
\hline
\end{tabular}

*M1 cases including all $\mathrm{N} 1$ cases $(\mathrm{n}=4)$, **Excluding nuclear grade $\mathrm{X}, * * *(\mathrm{n}=)$ as analyzed case number, ****including post-operative metastasis. INF: Infiltration; v: venous invasion; ly: lymphatic invasion; eg: expansive growth; ig: invasive growth; fc: false capsule; im: intrarenal metastasis; rc-inf: renal capsule-infiltration; rp-inf: renal pelvis-infiltration; s-inf: sinus-infiltration; SD: standard deviation.

Among the histologic types of RCC, clear cell carcinoma with pseudocapsules accounted for the highest proportion (Table IV). Cases with high nuclear grade and those that were highly invasive had fewer pseudocapsules; no relationship between pseudocapsule formation and venous invasion was recognized (Table IV). Pseudocapsule formation was significantly less in the s-inf1 cases than in the s-inf0 cases; however, its incidence was comparable between the rc-inf0 and rc-inf1 cases and between rp-inf1 and rp-inf0 cases (Table IV).

\section{Discussion}

To the best of our knowledge, the value of the Fourth Edition of the General Rule for Clinical and Pathological Studies on $\mathrm{RCC}$ in predicting metastasis has not been evaluated. In this study, each pathological item that was added to the current guidelines was evaluated and was useful in predicting all metastatic cases. Past reports showed the usability of immunohistochemical methods for predicting the prognosis of RCC patients $(14,15)$, and in addition, this study showed that morphological pathological items were useful in the same way.

Multifocal RCCs have been reported; in particular, nonhereditary sporadic ipsilateral multiple RCC was reported to have a prevalence of $6.8 \%$ (16). For ipsilateral multiple RCC, multiple synchronous cancers and $\mathrm{im} 1$, as defined by the current guidelines, are possible. In this study, im1 was diagnosed only by pathologic evaluation, not by preoperative imaging evaluation. Past reports showed that the rates of occult multifocal RCC ranged between $3.5 \%$ and $25 \%$ (10) 
Table IV. Relation between tumor pseudocapsule and other items (Percentage showing the $f_{c} 0$ or $f_{c} 1$ proportion of each item)

\begin{tabular}{lccc}
\hline Variable & $\mathrm{fc} 0$ & $\mathrm{fc} 1$ & $p$-Value \\
\hline Number of cases & $113(24.7 \%)$ & $344(75.3 \%)$ & \\
Size, cm ( \pm SD) & $4.6( \pm 3.4)$ & $3.7( \pm 2.3)$ & 0.001 \\
Histologic subtype & & & 0.011 \\
$\quad$ Clear cell & $87(21.9 \%)$ & $310(78.1 \%)$ & \\
Papillary & $8(33.3 \%)$ & $16(66.7 \%)$ & \\
Chromophobe & $6(42.9 \%)$ & $8(57.1 \%)$ & \\
Others & $12(54.5 \%)$ & $10(45.5 \%)$ & \\
* Nuclear grade 0 & $8(21.6 \%)$ & $29(78.4 \%)$ & 0.006 \\
1 & $63(20.8 \%)$ & $29(79.2 \%)$ & \\
2 & $38(34.5 \%)$ & $72(65.5 \%)$ & \\
INF & & & \\
a & $68(19.3 \%)$ & $285(80.7 \%)$ & 0.003 \\
b & $43(42.2 \%)$ & $59(57.8 \%)$ & \\
c & $2(100 \%)$ & $0(0.0 \%)$ & \\
eg & $76(19.9 \%)$ & $306(80.1 \%)$ & $<0.001$ \\
ig37 (49.3\%) & $38(50.7 \%)$ & & \\
v0 & $48(21.7 \%)$ & $173(78.3 \%)$ & 0.149 \\
v1 & $65(27.5 \%)$ & $171(72.5 \%)$ & \\
ly0 & $93(22.7 \%)$ & $317(77.3 \%)$ & 0.003 \\
ly1 & $20(42.6 \%)$ & $27(57.4 \%)$ & \\
im0 & $82(24.1 \%)$ & $259(76.0 \%)$ & 0.161 \\
im1 & $4(44.4 \%)$ & $5(55.6 \%)$ & \\
rc-inf0 & $85(22.9 \%)$ & $286(77.1 \%)$ & 0.062 \\
rc-inf1 & $28(32.6 \%)$ & $58(67.4 \%)$ & \\
rp-inf0 & $85(25.2 \%)$ & $252(74.8 \%)$ & 0.331 \\
rp-inf1 & $7(35.0 \%)$ & $123(65.0 \%)$ & \\
s-inf0 & $67(21.5 \%)$ & $244(78.5 \%)$ & $<0.001$ \\
s-inf1 & $27(50.9 \%)$ & $26(49.1 \%)$ & \\
\hline
\end{tabular}

*Excluding nuclear grade X. INF: Infiltration; v: venous infiltration; ly: lymphatic infiltration; eg: expansive growth; ig: invasive growth; fc: false capsule; im: intrarenal metastasis; rc-inf: renal capsule- infiltration; rp-inf renal pelvis-infiltration; s-inf: sinus-infiltration; SD: standard deviation.

and that the local recurrence rates after NSS ranged between $0.0 \%$ and $5.9 \%$ (17). Local recurrence, which might be partially caused by occult multifocal RCC, can be prevented by RN. However, CSS and PFS were almost the same between PN and RN (6-9). The results of this study suggested that ipsilateral im1 cases have a high possibility for distant metastasis; therefore, the presence of local residual metastatic cancer after PN might not affect the prognosis.

The probability of recurrence was reported to be the same regardless of the SM status (18-20). The growth and metastasis of small local residual cancer might be prevented by the immune system. An inverse correlation between the occurrence of occult multifocal RCC and the diameter of the cancer was reported (10); however, these evaluations did not account for the presence of ipsilateral im1 and synchronous multiple cancers. Based on our results, cases with ipsilateral im1 should be considered to have different characteristics from cases with ipsilateral multiple synchronous renal cancers. Pathologically, a diagnosis of im 1 is based on variations in size, homology of the histologic image, and the presence of vascular invasion. A report on the genomic signatures of multifocal clear cell RCC showed evidence on the independent origin of multifocal RCCs in $46 \%$ (21); therefore, accurate diagnosis of im1 might be sometimes difficult.

To preserve maximum renal function after PN, TE might be desirable because it allows maximum preservation of the renal parenchyma. The probability of having a tumor pseudocapsule as a thin rim of tissue surrounding the tumor was reported as $67 \%$ to $100 \%(22,23)$; in this study, the tumor pseudocapsule was observed in $75.3 \%$. A tumor pseudocapsule is composed of interstitial fibrosis with associated collagen deposition, glomerulo- and arteriosclerosis; tumor infiltration of the pseudocapsule is sometimes observed (23). In this study, many cases demonstrated tumor invasion beyond the pseudocapsule. One report stated that even if the tumors invade beyond the pseudocapsule, cancer cells can be separated from the SM by a thin layer of normal tissue with signs of lymphoplasmocytic inflammation (22). Therefore, TE using blunt dissection for any case of RCC may allow achievement of negative SM, even if cancer infiltration goes beyond tumor capsule. In fact, cases with positive SM after TE were reported to be less than that after standard PN; in addition, the CSS after TE was favorable (22, 24, 25). TE for RCC might be more useful than standard PN; however, reports on its benefit are not so many and more investigations would be required.

This study had several limitations. Different pathologists diagnosed this study population and few variations might be possible. The thickness of the tissue preparations was perfect for evaluation of vascular and lymphatic invasion, but not for evaluation of the nearby surrounding tissues. Evaluations of the tumor pseudocapsule did not include detailed information on continuities, thickness, and characteristics of the pseudocapsule. In this study, nuclear grade was evaluated not by the worldwide Fuhrman grade, but by the Japanese threegrade system; therefore, our results might be difficult to compare with the other reports in this point. The follow-up period was not so long; therefore, the number of metastatic cases might have increased further after the follow-up period.

\section{Conclusion}

This is the first report showing each item of the General Rule for Clinical and Pathological Studies on RCC, Fourth Edition in Japan was useful for predicting metastasis. PN might control cancer, even multifocal RCC. The indication of partial nephrectomy was appropriate in this cohort.

TE for RCC might be valuable in both preserving renal function and maintaining cancer control; however, more investigations would be needed. 


\section{Conflicts of Interest}

The Authors declare no conflicts of interest.

\section{References}

1 Go AS, Chertow GM, Fan D, McCulloch CE and Hsu CY: Chronic kidney disease and the risks of death, cardiovascular events, and hospitalization. N Eng J Med 351: 1296-1305, 2004.

2 Lucas SM, Stern JM, Adibi M, Zeltser IS, Cadeddu JA and Raj GV: Renal function outcomes in patients treated for renal masses smaller than $4 \mathrm{~cm}$ by ablative and extirpative techniques. J Urol 179: 75-79, 2008.

3 Huang WC, Elkin EB, Levey AS, Jang TL and Russo P: Partial nephrectomy versus radical nephrectomy in patients with small renal tumors is there a difference in mortality and cardiovascular outcomes? J Urol 181: 55-61, 2009.

4 Zini L, Perrotte P, Capitanio U, Jeldres C, Shariat SF, Antebi E, Saad F, Patard JJ, Montorsi F and Karakiewicz PI: Radical versus partial nephrectomy: effect on overall and noncancer mortality. Cancer 115: 1465-1471, 2009.

5 Huang WC, Levey AS, Serio AM, Snyder, M, Vickers AJ, Raj GV, Scardino PT and Russo P: Chronic kidney disease after nephrectomy in patients with renal cortical tumours: a retrospective cohort study. Lancet Oncol 7: 735-740, 2006.

6 Joniau S, Vander Eeckt K and Van Poppel H: The indications for partial nephrectomy in the treatment of renal cell carcinoma. Nat Clin Pract Urol 3: 198-205, 2006.

7 Gilbert SM, Russo P, Benson MC, Olsson CA and McKiernan JM: The evolving role of partial nephrectomy in the management of renal cell carcinoma. Curr Oncol Rep 5: 239-244, 2003.

8 Van Poppel H, Da Pozzo L, Albrecht W, Matveev V, Bono A, Borkowski A, Colombel M, Klotz, L, Skinner E, Keane T, Marreaud S, Collette S and Sylvester R: A prospective, randomised EORTC intergroup phase 3 study comparing the oncologic outcome of elective nephron-sparing surgery and radical nephrectomy for low-stage renal cell carcinoma. Eur Urol 59: 543-552, 2011.

9 Lee HJ, Liss MA and Derweesh IH: Outcomes of partial nephrectomy for clinical $\mathrm{T} 1 \mathrm{~b}$ and $\mathrm{T} 2$ renal tumors. Curr Opin Urol 24: 448-452, 2014.

10 Tsivian M, Moreira DM, Caso JR, Mouraviev V, Madden JF, Bratslavsky G, Robertson CN, Albala DM and Polascik TJ: Predicting occult multifocality of renal cell carcinoma. Eur Urol 58: 118-126, 2010.

11 Lapini A, Serni S, Minervini A, Masieri L and Carini M: Progression and long-term survival after simple enucleation for the elective treatment of renal cell carcinoma: experience in 107 patients. J Urol 174: 57-60, 2005

12 Carini M, Minervini A, Lapini A, Masieri L and Serni S: Simple enucleation for the treatment of renal cell carcinoma between 4 and $7 \mathrm{~cm}$ in greatest dimension: progression and long-term survival. J Urol 175: 2022-2026, 2006.

13 General Rule for Clinical and Pathological Studies on Renal Cell Carcinoma The 4th Edition. The Japanese Urological Association TJSoP, Japan Radiological Society. Kanahara \& Co., Ltd, Tokyo, 2011.

14 Virman J, Soini Y, Kujala P, Luukkaala T, Salminen T, Sunela K and Kellokumpu-Lehtinen PL: Claudins as prognostic factors for renal cell cancer. Anticancer Res 34: 4181-4187, 2014.
15 Virman J, Bono P, Luukkaala T, Sunela K, Kujala P and Kellokumpu-Lehtinen PL: VEGFR3 and CD31 as prognostic factors in renal cell cancer. Anticancer Res 35: 921-927, 2015.

16 Sorbellini M and Bratslavsky G: Decreasing the indications for radical nephrectomy: a study of multifocal renal cell carcinoma. Front Oncol 2: 84, 2012.

17 Van Poppel H: Efficacy and safety of nephron-sparing surgery. Int J Urol 17: 314-326, 2010.

18 Bensalah K, Pantuck AJ, Rioux-Leclercq N, Thuret R, Montorsi F, Karakiewicz PI, Mottet N, Zini L, Bertini R, Salomon L, Villers A, Soulie M, Bellec L, Rischmann P, De la Taille A, Avakian R, Crepel M, Ferriere JM, Bernhard JC, Dujardin T, Pouliot F, Rigaud J, Pfister C, Albouy B, Guy L, Joniau S, van Poppel H, Lebret T, Culty T, Saint F, Zisman A, Raz O, Lang H, Spie R, Wille A, Roigas J, Aguilera A, Rambeaud B, Martinez Pineiro L, Nativ O, Farfara R, Richard F, Roupret M, Doehn C, Bastian PJ, Muller SC, Tostain J, Belldegrun AS and Patard JJ: Positive surgical margin appears to have negligible impact on survival of renal cell carcinomas treated by nephron-sparing surgery. Eur Urol 57: 466-471, 2010.

19 Kwon EO, Carver BS, Snyder ME and Russo P: Impact of positive surgical margins in patients undergoing partial nephrectomy for renal cortical tumours. BJU Int 99: 286-289, 2007.

20 Antic T and Taxy JB: Partial nephrectomy for renal tumors: lack of correlation between margin status and local recurrence. Am J Clin Pathol 143: 645-651, 2015.

21 Cheng L, MacLennan GT, Zhang S, Zhou M, Tan PH, Foster S, Lopez-Beltran A and Montironi R: Evidence for polyclonal origin of multifocal clear cell renal cell carcinoma. Clin Cancer Res 14: 8087-8093, 2008.

22 Minervini A, di Cristofano C, Lapini A, Marchi M, Lanzi F, Giubilei G, Tosi N, Tuccio A, Mancini M, della Rocca C, Serni S, Bevilacqua $G$ and Carini $M$ : Histopathologic analysis of peritumoral pseudocapsule and surgical margin status after tumor enucleation for renal cell carcinoma. Eur Urol 55: 1410-1418, 2009.

23 Azhar RA, de Castro Abreu AL, Broxham E, Sherrod A, Ma Y, Cai J, Gill TS, Desai M and Gill IS: Histological analysis of the kidney tumor-parenchyma interface. J Urol 193: 415-422, 2015.

24 Minervini A, Ficarra V, Rocco F, Antonelli A, Bertini R, Carmignani G, Cosciani Cunico S, Fontana D, Longo N, Martorana G, Mirone V, Morgia G, Novara G, Roscigno M, Schiavina R, Serni S, Simeone C, Simonato A, Siracusano S, Volpe A, Zattoni F, Zucchi A and Carini M: Simple enucleation is equivalent to traditional partial nephrectomy for renal cell carcinoma: results of a nonrandomized, retrospective, comparative study. J Urol 185: 1604-1610, 2011.

25 Longo N, Minervini A, Antonelli A, Bianchi G, Bocciardi AM, Cunico SC, Fiori C, Fusco F, Giancane S, Mari A, Martorana G, Mirone V, Morgia G, Novara G, Porpiglia F, Raspollini MR, Rocco F, Rovereto B, Schiavina R, Serni S, Simeone C, Verze P, Volpe A, Ficarra V and Carini M: Simple enucleation versus standard partial nephrectomy for clinical T1 renal masses: perioperative outcomes based on a matched-pair comparison of 396 patients (RECORd project). Eur J Surg Oncol 40: 762-768, 2014.

Received June 25, 2017 Revised July 8, 2017 Accepted July 10, 2017 